\title{
Correction to: Doppler Ultrasonographic Anatomy of the Midline Nasal Dorsum
}

\author{
Hyoung-Jin Moon' ${ }^{1}$ Won $\mathrm{Lee}^{2} \cdot$ Do Hyun $\mathrm{Kim}^{3} \cdot$ Il Hwan Lee ${ }^{3}$ Soo Whan Kim ${ }^{3}$
}

Published online: 11 June 2021

(C) Springer Science+Business Media, LLC, part of Springer Nature and International Society of Aesthetic Plastic Surgery 2021

\section{Correction to:}

Aesth Plast Surg (2021) 45:1178-1183

https://doi.org/10.1007/s00266-020-02025-1

Do Hyun Kim's name appeared incorrectly on the original publication of this article. It appears correctly here.
Publisher's Note Springer Nature remains neutral with regard to jurisdictional claims in published maps and institutional affiliations.

The original article can be found online at https://doi.org/10.1007/ s00266-020-02025-1.

Soo Whan Kim

kshent@catholic.ac.kr

1 Beup Facial Plastic Surgery Clinic, Seoul, South Korea

2 Yonsei E1 Plastic Surgery Clinic, Anyang, South Korea

3 Department of Otolaryngology-Head and Neck Surgery, College of Medicine, Seoul St. Mary's Hospital, The Catholic University of Korea, Banpo-daero 222, Seocho-gu, Seoul 06591, Korea 